\title{
Nail-gun Injury through the Spinal Canal
}

\author{
Mark Bigder, Fred Zeiler, Neil Berrington
}

Keywords: Neurosurgery, neurotrauma, neurovascular

A 27-year-old man presented to our trauma centre after having sustained an accidental nail-gun injury resulting in a penetrating wound to the left lateral aspect of his neck. He arrived to hospital via ambulance with cervical spinal precautions in place. Upon arrival he was found to be hemodynamically stable and neurologically intact. He described an initial transient 'electric' like sensation in his arms and legs at the time of the accident, which promptly resolved and was no longer present at the time of arrival. A computed tomogram (CT) angiogram was performed to assess the relationship between the nail, vertebral, and carotid arteries as well as the spinal canal. The nail measured $3.5 \mathrm{~cm}$ and was noted to pass posteriorly, in close proximity to the vertebral artery, through the left C1-C2 neural foramen (Figure 1A, Figure 2B), coming to rest with the tip of the nail in the centre of the spinal canal (Figure 1B, Figure 2A). Based on the CT, there did not appear to be any barbs on the nail. Remarkably, there was no evidence of injury to the vertebral arteries on imaging and the patient remained neurologically intact.

Following initial imaging, the patient was transferred to the operating room and the nail was removed without complications by simply pulling along the trajectory of the nail. A CT angiogram was repeated immediately following removal and showed no injury to the major vessels, hemorrhage or pseudomeningocele (Figure 3). At two-month follow-up, the patient was asymptomatic with no signs of complication or infection.

\section{DisCUSSION}

Penetrating neck injuries account for approximately $5 \%$ to $10 \%$ of all trauma admissions. ${ }^{1}$ Given the intimate relationship of the numerous vital structures in the neck, penetrating wounds may result in devastating injury to vital vascular and neurological structures as well as to the trachea and esophagus. Penetrating neck injuries are associated with vascular injury in approximately $25 \%$ of cases. Remarkably, overall mortality is low ranging from $0 \%$ to $11 \%$ in various series. ${ }^{2,3}$ In a review of 130 patients with penetrating neck injuries presenting to our centre, knife stabbings were identified as the most common mechanism of penetrating neck injury occurring in 79 patients. ${ }^{4}$ Nail-gun injuries to the neck are uncommon occurrences. This case provides an interesting and rare imaging finding demonstrating a nail situated in the spinal canal of a patient with no neurological compromise.

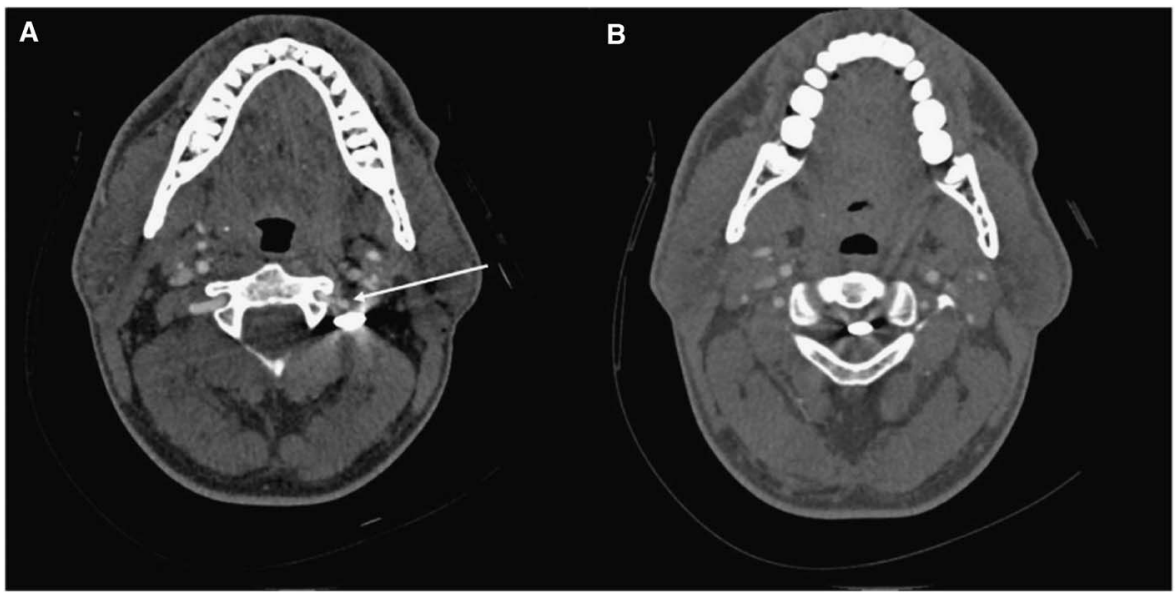

Figure 1: Axial CT Angiogram of the Neck A: Axial CT-Angiogram displaying proximity of nail to the left vertebral artery as it exits the foramen transversarium at $C 2$. The white arrow indicates the left vertebral artery. B: Axial CT-Angiogram displaying the tip of the nail in the center of the spinal canal between $C 1$ and $C 2$.

\footnotetext{
From the Section of Neurosurgery, Dept of Surgery, University of Manitoba, Winnipeg, Manitoba, Canada. Received August 1, 2014. Final Revisions Submitted January 22, 2014.

Correspondence to: Mark Bigder, University of Manitoba - Section of Neurosurgery, GB129-820 Sherbrook Street, Health Sciences Centre, Winnipeg, Manitoba, R3T 2N2, Canada. E-mail: umbigder@myumanitoba.ca
} 


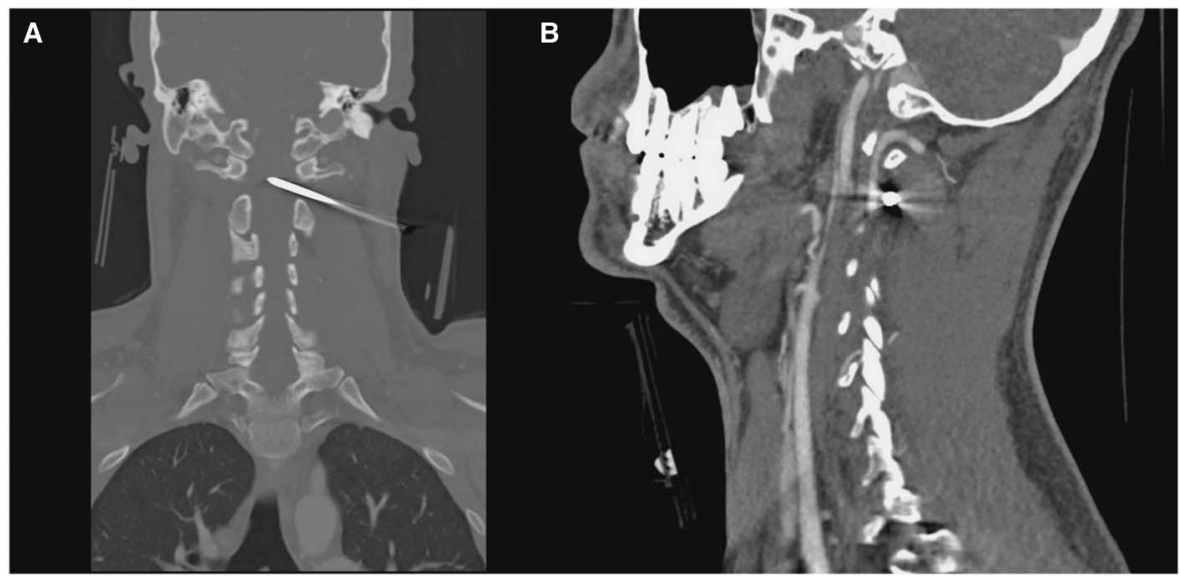

Figure 2: Coronal and Sagittal CT-Angiogram Images A: Coronal CT-Angiogram displaying bone windowing with the trajectory of the nail seen. The nail tip is located in the center of the spinal canal at the level of C1-C2. B: Sagittal CT-Angiogram displaying the proximity of the nail to the ascending left vertebral artery, with the nail passing posterior to the vessel.

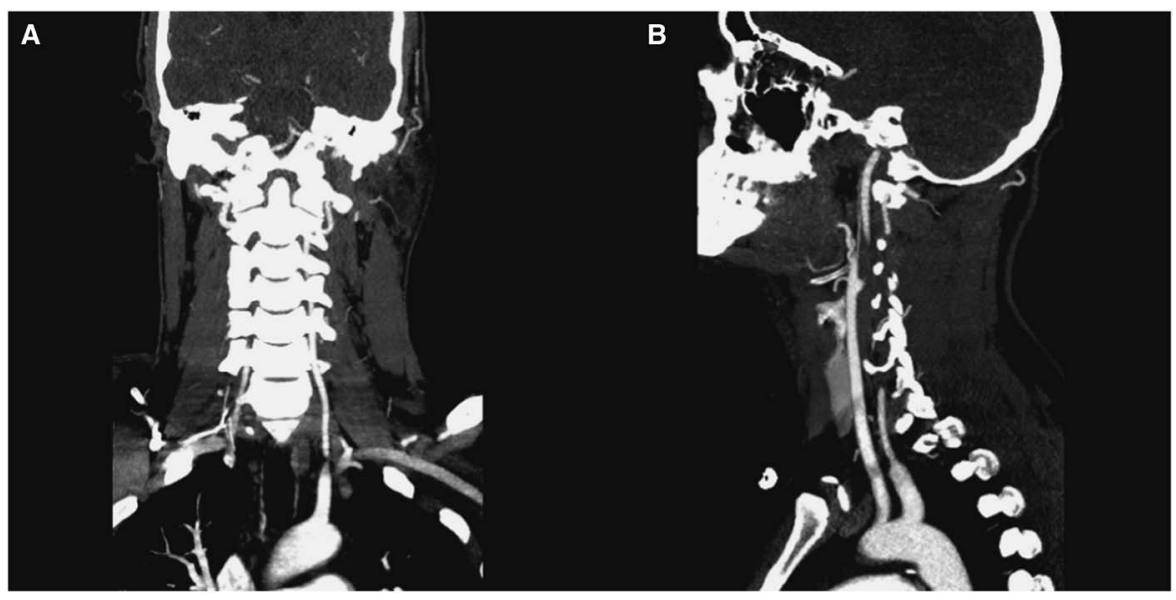

Figure 3: Post-Extraction Coronal and Sagittal CT-Angiogram A and B: Coronal and Sagittal CT-Angiogram with bone windowing displaying a patent left vertebral artery following nail extraction. There is no sign of vascular injury to the carotid or vertebral artery and no sign of hemorrhage or pseudomeningocoele surrounding the nail trajectory site.

Management is challenging, as care must be taken to avoid injury to the spinal cord, exiting nerve root as well as vertebral and carotid arteries. Patients must be monitored for cerebrospinal fluid leak, infection and vascular injury in the postoperative period. To our knowledge, this is the first case at our centre of a nail-gun injury to the neck and appears to be a mechanism of injury rarely described in the literature. ${ }^{5}$ Among this group, nail-gun injuries involving the spinal canal are even less common.

\section{Disclosures}

The authors have nothing to declare.

\section{REFERENCES}

1. Demetriades D, Asensio JA, Velmahos G, Thal E. Complex problems in penetrating neck trauma. Surg Clin North Am. 1996;6:661-83.

2. Asensio JA, Valenziano CP, Falcone RE, Grosh JD. Management of penetrating neck injuries. The controversy surrounding zone II injuries. Surg Clin North Am. 1991;71:267-96.

3. McConnel DB, Trunkey DD. Management of penetrating trauma of the neck. Adv Surg. 1994;27:97-127.

4. Nason RW, Assuras GN, Gray PR, Lipschitz J, Burns CM. Penetrating neck injuries: analysis of experience from a Canadian trauma centre. Can J Surg. 2001;44:122-6.

5. Nathoo N, Sarkar A, Varma G, Mendel E. Nail-gun injury of the cervical spine: simple technique for removal of a barbed nail. J Neurosurg Spine. 2011;15:60-3. doi: 10.3171/2011.3.SPINE10718. Epub 2011 Apr 1. 